\title{
Association between mood states and performance of Brazilian elite sailors: Winners vs. non-winners
}

\author{
Asociación entre estado de ánimo y el rendimiento de regatistas \\ brasileños de élite: Ganadores vs. no ganadores
}

\author{
Ricardo Brandt ${ }^{1}$, Maick da Silveira Viana ${ }^{2}$, Tania Brusque Crocetta ${ }^{3}$, Alexandro Andrade ${ }^{3}$ \\ 1 Centro de Ciências Humanas, Educação e Letras. Universidade Estadual do Oeste do Paraná. Brasil. \\ 2 Campus Joinville. Instituto Federal de Santa Catarina. Brasil. \\ 3 Centro de Ciências da Saúde e do Esporte. Universidade do Estado de Santa Catarina. Brasil.
}

CORRESPONDENCIA:

Ricardo Brandt

ricabrandt@gmail.com

\begin{abstract}
Sailing is a sport that requires optimum emotional balance for athletes to be able to yield optimum performances, given its unique peculiarities, where six mood states are identified as decisive, such as, high level of vigor and lower levels of tension, depression, anger, fatigue and mental confusion. The purpose of this study is to assess the association between mood states and athletic performance of sailors in different high performance competitions. Sixty-two elite sailors of single-handed and group classes participated in four major competitions. Assessment was carried out at the competition venues and the mood state was assessed using the Brunel Mood Scale. First-place winners in the four competitions showed different mood states from those who finished the races in other positions, especially taking into account depression $(p<0.01)$, vigor $(p<0.001)$ and fatigue $(p<0.001)$. Sailors with lower depression $(O R=0.70)$ and fatigue levels $(O R=$ $0.80)$, and greater vigor levels $(O R=1.26)$ proved to be more likely to win the race. The results corroborate the available scientific data focusing on the relationship between mood states and athletic performance.
\end{abstract}

Key words: Sailing, mood state, sport performance.

\section{Resumen}

Debido a sus peculiaridades, la navegación a vela es un deporte que requiere un equilibrio emocional óptimo de los atletas para obtener un alto rendimiento, en el que se identificaron seis estados de ánimo como decisivos para el mejor rendimiento deportivo; por ejemplo: alto nivel de vigor y niveles más bajos de tensión, depresión, ira, fatiga y confusión mental. El objetivo de este estudio es evaluar la asociación entre los estados de ánimo y el rendimiento deportivo de los atletas que practican navegación a vela en diferentes competencias. Participaron en esta investigación sesenta y dos navegantes de alto nivel en clases colectivas e individuales, en cuatro competencias diferentes de vela. Las evaluaciones se realizaron en los lugares de las competencias y para valorar el estado de ánimo se utilizó la escala de ánimo de Brunel. Los ganadores presentaron diferentes estados de ánimo. Atletas con menor depresión ( $p$ $<0.01),(O R=0.70)$ y fatiga $(p<0.001),(O R=0.80)$ y mayor vigor $(p<0.001),(O R=1.26)$ son más propensos a ganar la competición. Los resultados revelaron la relación entre estados de ánimo y el rendimiento deportivo.

Palabras clave: Navegación a vela, estado de ánimo, rendimiento deportivo. 


\section{Introduction}

Recent research has highlighted mental abilities in sports context by crediting them with an important role among the factors that influence performance (Bertollo, Saltarelli, \& Robazza, 2009; Manzanares, Menayo, Segado, Salmerón, \& Cano, 2015). This role is evident especially in elite sports in which athletes' physical and technical skills are similar, so psychological factors may be decisive in winning a competition (Allen \& De Jong, 2006; Totterdell \& Leach, 2001). Although sport psychology technique has not yet been adequately taken up on as a regular procedure either in athletic individual or group performances, Dosil (2004) believes that in the future, coaches of different sports will include it in their training sets.

Emotional states such as excitement, happiness, sadness, anguish -to mention a few- occur over a variable length of time, which can range from a few hours to several days. Moods may also vary in intensity, involving negative states (such as tension, depression, anger, fatigue and mental confusion) as well as positive ones (vigor) (Lane \& Terry, 2000; Terry, Lane, \& Fogarty, 2003). In sports, mood states can lead to decisive factors; moreover, some authors even consider that they partially explain the successful performance of athletes in a competition (Devonport, Lane, \& Hanin, 2005; Rohlfs, de Carvalho, Rotta, \& Krebs, 2004).

In general, it is considered that the moods most associated with good athletic performance are high vigor associated with low level of fatigue, anger, stress, depression and mental confusion (Lane \& Terry, 2000), so that under those conditions the athlete can present their best performance (Bertollo et al., 2009; Micklewright, Griffin, Gladwell, \& Beneke, 2005). Alterations in these factors negatively influence cognition, decision-making and motor skills (Werneck, Bara Filho, \& Ribeiro, 2006), thus jeopardizing either their training or their performance during competition (Devonport et al., 2005; Werneck et al., 2006).

Changes in mood states may be caused by different factors such as the pressure caused by the sports context, demand for results, accumulation of events, insufficient intervals for recovering, excessive training and many other conditions which might lead athletes to overexert themselves physically and psychologically. It is also possible that some factors should be taken into account according to different sorts of sports and their related psychological peculiarities (Brandt, Viana, Segato, \& Andrade, 2010), thus demonstrating the importance of investigating the psychological peculiarities concerning the various sports.
Sailing is recognized as an interesting sport as regards psychological aspects (Rotunno, Senarega, \& Reggiani, 2004). Among the challenging features that the athlete is subjected to are winds, tides, the settings of the boat, and opponents meaning that, athletes deal constantly with unstable and unpredictable situations (Brandt et al., 2010; Segato, Brandt, Liz, Vasconcellos, \& Andrade, 2010).

The commitment to sailing, the professionalization of the sport and the search for better performance make sailors of different competitive levels seek to engage in programs that help them achieve the best psychological preparation and a competitive advantage over their competitors (Lane \& Terry, 2000). All these factors have already been highlighted by Shephard (1997) and Pluijms, Canãl-Bruland, Hoozemans, \& Savelsbergh (2015), who states that sailing is a sport that demands not only physical and tactical skills but good psychological preparation as well.

Meta-analysis has shown (Beedie, Terry, \& Lane, 2000; LeUnes \& Burger, 2000) that the characteristics of mood states can predict the performance of athletes in different sports. The question is whether this feature can be identified in elite sailors from their performances in different races.

Even though there is widespread recognition of the importance of mood states in sports performance and overall health, relatively little is known about the emotional patterns of sailors during sporting competitions (Olmedilla, Ortega, González, \& Serpa, 2015).

Within this framework, this study aimed to describe the levels of mood and athletic performance of elite Brazilian sailors; and to analyze the association between their mood states and athletic performance.

\section{Methods}

\section{Subjects}

Participants were 62 Brazilian elite sailors (mean age 23 years, $s d=7.2$ ), 27 men (mean age 24 years, $s d=6.6$ ) and 35 women (mean age 23 , $s d=7.6$ ), of individual and group classes who had participated in four major competitions in Brazil: the 2007 PanAmerican Games, the 2007 Pre-Pan-American sailing, the 2007 Pre-Olympic sailing, and the 2009 PreOlympic sailing. Various classes of athletes competed in both individual (Rs:X, Sunfish, Laser Radial, Laser Standard) and collective craft (Snipe, HobCat 16, J-24, Match Race, Tornado) races. Participants were chosen in such a way that all competitors from the 
Table 1. Dimensions of Brunel Mood Scale (BRUMS)

\begin{tabular}{ll}
\hline Dimension & Definition \\
\hline Tension & State of musculoskeletal tension and worry. \\
Depression & Emotional state of despondency, sadness, and unhappiness. \\
Anger & State of hostility towards others. \\
Vigour & State of energy and physical stamina. \\
Fatigue & State of tiredness or low energy. \\
Mental confusion & State of light-headedness and instability in emotions. \\
\hline
\end{tabular}

Note: Source: Brandt et al. (2010).

four competitions had the opportunity to participate in the study.

\section{Instruments}

Mood states were evaluated using the Brunel Mood Scale (BRUMS) (Terry et al., 2003). The BRUMS was translated into Portuguese and validated for a Brazilian population by Rohlfs et al. (2008). The instrument comprises 24 items rated on a five-point scale (ranging from $0=$ no to 4 = extremely). Ratings reflected their moods at the time of evaluation. The BRUMS comprises six dimensions (see Table 1), each consisting of four items. The total score of each dimension ranges from 0 to 16 . The internal consistency values (Cronbach's alpha) of all six dimensions and the total scale were all greater than 0.76 in Rohlfs et al. (2008), while in the present study the total scale was 0.841 (Tension 0.736; Depression 0.891; Anger 0.856; Vigour 0.789; Fatigue 0.654; Mental confusion 0.541).

Results obtained by the athlete: The results achieved by sailors in races and the outcomes of the races were obtained from summaries provided by the Brazilian Sailing and Motor Federation (CBVM).

\section{Procedure}

This study was approved by the Ethics Committee for Research of the State University of Santa Catarina ( $\left.n^{\circ} 33 / 2007\right)$. Data collection was performed up to 60 minutes before the sailors' competitions. Due to standardized privacy conditions and supervision of athletes, we attempted to collect data before athletes were actually competing in national and international competitions. After being invited to participate in the study, sailors who agreed to collaborate signed the Free and Informed Consent Form. Additionally, sailors under the age of 18 had their form signed by a parent or legal guardian. Assessments of mood states were carried out approximately 30 minutes before the beginning of the competition, where it took place. Given the importance of the competition in question and the commitment of the sailors, the researchers tried to interfere minimally with the concentration and preparation of the sailors, as recommended by CBVM. In this way, the sailors participated in the survey whenever they judged the most appropriate moment, with the researchers on hand to provide any necessary clarification to the sailors.

\section{Data analyses}

Statistical analyses were performed using SPSS version 21 (IBM Corporation, Armonk, NY). Descriptive analysis of variables was performed using averages and standard deviation. The U Mann-Whitney test was applied to compare the differences in the mood states of men and women, first-place winners and those who took other positions. Gender-controlled partial correlation was used to investigate the relationship between the placement of the sailors in the races and their mood states. In the logistical regressive analysis, mood states were applied as dependent variables and coming in first place in the race as the outcome, which yielded the odds/ratio and the respective confidence interval of $95 \%$. The significance level was set at $p<0.05$.

\section{Results}

In comparing the mood states of male and female sailors, significant differences between genders were revealed, both in the overall analysis involving the entire sample, and in the analysis performed separately for each competition (Table 2). However, a trend has been noticed that female participants indicate in general higher levels of depression and anger and less vigor than males.

The correlation analyses controlled by gender shows a weak relationship among placing in the competitions and depression $(r=0.264 / p<0.05)$, vigor $(r=-0.248 / p<0.05)$ and $\backslash$ fatigue $(r=0.283 / p$ $<0.05)$. When the same analyses are performed with separation of the samples of different competitions, there was a significant association between place in 
Table 2. Mood state of sailors (men and women) in four different races

\begin{tabular}{|c|c|c|c|c|c|c|c|c|c|c|c|c|}
\hline & \multicolumn{2}{|c|}{ Tension } & \multicolumn{2}{|c|}{ Depression } & \multicolumn{2}{|c|}{ Anger } & \multicolumn{2}{|c|}{ Vigor } & \multicolumn{2}{|c|}{ Fatigue } & \multicolumn{2}{|c|}{ Confusion } \\
\hline & $\bar{x}$ & \pm & $\bar{x}$ & \pm & $\bar{x}$ & \pm & $\bar{x}$ & \pm & $\bar{x}$ & \pm & $\bar{x}$ & \pm \\
\hline \multicolumn{13}{|l|}{ Overall Sample } \\
\hline Men $(n=27)$ & 4.5 & 3.4 & 1.7 & 2.6 & 2.1 & 2.9 & 10.2 & 3.3 & 5.2 & 3.4 & 2.7 & 4.0 \\
\hline Women $(n=35)$ & 5.0 & 3.8 & 2.6 & 2.8 & 3.0 & 3.9 & 8.7 & 3.4 & 5.7 & 3.9 & 2.9 & 2.0 \\
\hline Total $(n=62)$ & 4.8 & 3.6 & 2.2 & 2.7 & 2.6 & 3.5 & 9.3 & 3.4 & 5.5 & 3.7 & 3.2 & 3.0 \\
\hline \multicolumn{13}{|c|}{2007 Pre-Pan American Games } \\
\hline Men $(n=12)$ & 4.7 & 3.6 & 2.1 & 2.9 & 2.3 & 3.5 & 9.2 & 3.6 & 6.5 & 3.7 & 4.8 & 5.0 \\
\hline Women $(n=5)$ & 6.2 & 4.6 & 3.4 & 4.3 & 4.4 & 5.4 & 8.8 & 3.7 & 3.8 & 3.0 & 2.8 & 3.0 \\
\hline Total $(n=17)$ & 5.1 & 3.8 & 2.5 & 3.3 & 2.9 & 4.1 & 9.1 & 3.5 & 5.7 & 3.7 & 4.2 & 5.0 \\
\hline \multicolumn{13}{|c|}{2007 Pan American Games } \\
\hline Men $(n=5)$ & 7.4 & 2.0 & 0.2 & 0.4 & 2.0 & 2.4 & 12.0 & 2.4 & 3.4 & 2.0 & 3.6 & 3.0 \\
\hline Women $(n=1)$ & 8.0 & - & 4.0 & - & 16.0 & - & 12.0 & - & 2.0 & - & 4.0 & - \\
\hline Total $(n=6)$ & 7.5 & 1.8 & 0.8 & 1.6 & 4.3 & 6.1 & 12.0 & 2.1 & 3.1 & 1.9 & 3.6 & 3.0 \\
\hline \multicolumn{13}{|c|}{2007 Pre-Olympic Games } \\
\hline Men $(n=2)$ & 2.0 & 1.4 & 1.5 & 2.1 & 1.5 & 0.7 & 12.0 & 2.8 & 3.0 & 2.8 & 1.0 & 1.0 \\
\hline Women $(n=6)$ & 7.3 & 2.8 & 2.5 & 1.8 & 2.0 & 1.6 & 11.1 & 1.1 & 4.3 & 2.2 & 5.0 & 2.0 \\
\hline Total $(n=8)$ & 6.0 & 3.4 & 2.2 & 1.8 & 1.8 & 1.4 & 11.3 & 1.5 & 4.0 & 2.2 & 4.0 & 3.0 \\
\hline \multicolumn{13}{|c|}{2009 Pre-Olympic Games } \\
\hline Men $(n=8)$ & 3.2 & 3.4 & 2.2 & 3.2 & 2.1 & 3.1 & 10.1 & 3.2 & 5.1 & 3.3 & 2.7 & 3.0 \\
\hline Women $(n=23)$ & 4.1 & 3.7 & 2.3 & 2.7 & 2.5 & 3.0 & 7.9 & 3.5 & 6.6 & 4.2 & 2.4 & 1.0 \\
\hline Total $(n=31)$ & 2.9 & 3.6 & 2.3 & 2.8 & 2.4 & 3.0 & 8.4 & 3.5 & 6.2 & 4.0 & 2.5 & 2.0 \\
\hline
\end{tabular}

Table 3. Mood state of sailors according to their final position (FP = First Place / OP = Other Position)

\begin{tabular}{|c|c|c|c|c|c|c|c|c|c|c|c|c|}
\hline & \multicolumn{2}{|c|}{ Tension } & \multicolumn{2}{|c|}{ Depression } & \multicolumn{2}{|c|}{ Anger } & \multicolumn{2}{|c|}{ Vigor } & \multicolumn{2}{|c|}{ Fatigue } & \multicolumn{2}{|c|}{ Confusion } \\
\hline & $\bar{x}$ & \pm & $\bar{x}$ & \pm & $\bar{x}$ & \pm & $\bar{x}$ & \pm & $\bar{x}$ & \pm & $\bar{x}$ & \pm \\
\hline \multicolumn{13}{|c|}{ Overall Sample } \\
\hline $\operatorname{FP}(n=16)$ & 5.1 & 3 & $0.9 *$ & 1.4 & 1.8 & 1.8 & $11 *$ & 2.2 & $3.7^{*}$ & 3 & 2.6 & 2 \\
\hline OP $(n=46)$ & 4.8 & 3.8 & $2.6^{*}$ & 2.9 & 2.9 & 3.9 & $8.8^{*}$ & 3.5 & $6.1 *$ & 3.7 & 3.5 & 3 \\
\hline \multicolumn{13}{|c|}{2007 Pan American Games } \\
\hline $\mathrm{FP}(n=4)$ & 7 & 2.1 & 0.2 & 0.5 & 2 & 2.8 & 13 & 2.5 & 3 & 2.1 & 2.5 & 2 \\
\hline OP $(n=2)$ & 8.5 & 0.7 & 2 & 2.8 & 9 & 9.8 & 11 & 1.4 & 3.5 & 2.1 & 6 & 3 \\
\hline \multicolumn{13}{|c|}{2007 Pre Pan American Games } \\
\hline $\mathrm{FP}(n=3)$ & 4.6 & 3.2 & 0.6 & 0.5 & 2.6 & 1.5 & 10 & 1.7 & $1.3 * *$ & 1.1 & 4.6 & 4 \\
\hline OP $(n=14)$ & 5.2 & 4.1 & 2.9 & 3.5 & 3 & 4.5 & 8.9 & 3.8 & $6.7 * *$ & 3.3 & 4.1 & 5 \\
\hline \multicolumn{13}{|c|}{2009 Pre-Olympic Games } \\
\hline $\mathrm{FP}(n=5)$ & 5.4 & 3.9 & 0.6 & 1.3 & 1.6 & 1.5 & 9.4 & 2.1 & 5.8 & 4.2 & 2 & 1 \\
\hline OP $(n=26)$ & 3.6 & 3.6 & 2.6 & 2.9 & 2.5 & 3.2 & 8.3 & 3.7 & 6.3 & 4.1 & 2.6 & 2 \\
\hline \multicolumn{13}{|c|}{2007 Pre-Olympic Games } \\
\hline $\mathrm{FP}(n=4)$ & $3 *$ & 1.6 & 2.2 & 2.2 & 1.5 & 1.2 & 12 & 1.6 & 3.7 & 1.8 & 2.2 & 2 \\
\hline OP $(n=4)$ & 9* & 1.1 & 2.2 & 1.7 & 2.2 & 1.7 & 11 & 1.2 & 3.2 & 2.8 & 5.7 & 2 \\
\hline
\end{tabular}

Note. ${ }^{*} p<0.05 ; * * p<0.00$

the competition with fatigue $(r=-0.593 / p=0.01)$ and tension $(r=-0.898 / p=0.01)$ in the 2007 Pre-PanAmerican race.

The results show differences in the mood states of the sailors who won first place (winners) in the competition ( $n=16)$ when compared to those who completed the competition in other positions $(n=46)$ (non-winners). In the general analyses, significant differences in depression $(p<0.05)$, vigor $(p<$ $0.05)$ and fatigue $(p<0.01)$ were shown, where the results show that the winners are less depressed and fatigued and felt more vigorous. Among the sailors who participated in the 2007 Pan-American Games and the 2009 Pre-Olympic Sailing, no significant differences were found in mood states among the winners and those who completed the competition in other positions (non-winners). However, in the 2007 Pre-Pan-American fatigue levels $(p<0.01)$ were significantly different between winners and the other participants. Regarding the 2008 Pre-Olympic Sailing, tension $(p<0.05)$ was significantly different between winners and other participants (Table 3 ). 
Table 4. Results of logistic regression predicting performance according to mood states $(n=62)$

\begin{tabular}{|c|c|c|c|c|}
\hline & Regression Coefficient (B) & $O R$ & $95 \% \mathrm{Cl}$ & $p$ \\
\hline Tension & 0.019 & 1.02 & $0.87-1.19$ & 0.80 \\
\hline Depression & -0.363 & 0.70 & $0.49-0.98$ & $0.04 *$ \\
\hline Anger & -0.105 & 0.90 & $0.74-1.10$ & 0.33 \\
\hline Vigor & 0.229 & 1.26 & $1.0-1.56$ & $0.04 *$ \\
\hline Fatigue & -0.218 & 0.80 & $0.66-0.98$ & $0.03 *$ \\
\hline Confusion & -0.104 & 0.90 & $0.72-1.13$ & 0.30 \\
\hline
\end{tabular}

Note. 95\% Cl: $95 \%$ confidence interval.

After regression analysis, taking placement as the variable outcome, it was found that factors such as depression, vigor and fatigue were significantly associated with outcome in the competition. With increase in vigor $(O R=1.26)$, fatigue $(O R=0.80)$ and depression $(O R=0.70)$ decreased, increasing the chances of winning the competition (Table 4).

\section{Discussion}

This study aimed to analyze the association between mood states and sport performance for Brazilian sailors in several high level competitions. It is a unique study involving a sample that encompasses international-level sailors. Especially in competitions with a high degree of personal importance for the competitors, changes in mood states can influence the athletes' performance (Lane, Whyte, Terry, \& Nevill, 2005; Micklewright et al., 2005; Terry \& Lane, 2000; Thelwell, Lane, \& Weston, 2007).

The participants were involved in major national competitions and Pan-American (Pre-Olympic, PrePan-American and Pan-American Games), and as a result the data were collected in realistic performances.

Differences between the moods of male and female sailors are perceived only in descriptive statistics, where women showed less vigor and greater tension, depression, anger, fatigue and confusion. These data corroborate the study of Brandt et al. (2010), who found the same differences in sailors, but also no statistical significance. Similarly, in research of Segato et al. (2010), investigating stress in male and female sailors, women had higher stress levels without significant statistical difference.

The research results provide empirical evidence of differences among the mood states of champion sailors and other participants. Objectively, the Brazilian champion, compared to the others, showed lower levels of depression and fatigue and higher vigor. A similar profile of moods was perceived in different competitions among the champions, with similar characteristics to the profile proposed by Morgan,
Oconnor, Ellickson, \& Bradley (1988), thus agreeing with the literature regarding mood profiles related to better performance in sports (Lane, Terry, Beedie, Curry, \& Clark, 2001; Lane et al., 2005; Micklewright et al., 2005; Terry \& Lane, 2000; Thelwell et al., 2007).

The correlations between mood factors and the position in which the athlete finished the competition also suggest an association between mood and the results achieved. Although those identified correlations are not as strong as in other research in which similar analyses were performed, low values of mood states with other variables were also identified (Lane et al., 2001; Lane et al., 2005; Zandi \& Rad, 2013). These rates are expected, because the psychological variables involve a series of intervening variables which interact as much with mood as with performance.

The logistical regression analysis was one more indication that mood is related to the performance of sailors in competition. The results have shown that with increased fatigue $(O R=0.80)$ and depression $(O R=0.70)$ the chances of winning decrease, while increase in vigor $(O R=1.26)$ raises the chances of obtaining success. In our literature review, no studies were identified which came to this conclusion. From this point of view, these results are innovative. Although these results have been shown to be adequate and also allowed for interesting inferences, it is necessary to make clear that this is not a situation of cause and effect, because it is a crosssectional study which cannot be conclusive.

We now discuss three specific factors that differ significantly between winners and other participants.

Depression: This variable represents a depressive state, in which personal inadequacy is felt, indicative of depressive mood rather than clinical depression (Galambos, Terry, Moyle, \& Locke, 2005). Among its features there are feelings such as negative self-esteem, emotional isolation, sadness, difficulty of adaptation, depreciation or negative self-image (Beck \& Clark, 1988; Watson, Clark, \& Tellegen, 1988) and despair (Schinka, Velicer, \& Weiner, 2003). To Rohlfs et al. (2008), depressive moods may be related to feelings of sadness due to failure to win. However, this study has shown that higher levels of depression during the competition increase the chances of the sailor losing, 
demonstrating that depression does not arise only as the consequence of a poor result, but may precede it, even causing or influencing it. This relationship deserves special attention in sports like sailing, which take place over long periods (e.g. a number of days) of competition and overall results are based on a series of accumulated results. It is important that throughout the competition sailor who achieve negative results in some races have the emotional support to manage the situation, so this fact does not impair their performance in future races.

Vigor: This was the only positive mood variable identified, representing a state of excitement, arousal, physical energy (Terry, 1995) and joy (Schinka et al., 2003) emotions which are essential for good performance of an athlete in competition. Studies have shown that low levels of vigor are normally associated with the increase of the negative mood factors' (Rohlfs et al., 2005; Terry et al., 2003), suggesting that although sporting performance is linked to vigor (Terry, 1995), it is not independently related to other factors. During a sailing competition, the reduction of vigor to very low levels can be detrimental to athletic performance, especially in sailing classes with higher energy demands (Laser Radial, Laser Standard, RS:X, Finn, among others) where the sailor feels his/her physical and emotional capacities to be diminished (Brandt et al., 2010). The physical actions required in sailing, such as moving the anchor and cable require strength and endurance throughout the race, which would be hampered by low vigor.

Fatigue: This quality represents a state of exhaustion, apathy and low energy. Symptoms of fatigue may gradually affect attention, concentration and memory, increasing irritability and causing changes in sleep (Schinka et al., 2003). Thus, increase in fatigue can affect physiological and psychological psychosomatic problems (Lane \& Terry, 2000; Schinka et al., 2003). Levels of fatigue may bet due to excessive tiredness or lack of rest, which is detrimental to sport performance, denoting bad fitness or/and mental preparation (Scott, McNaughton, \& Polman, 2006). Fatigue occurs on two levels: a) on a physiological level, due to the physical practice with high energy demands, causing physical exhaustion; b) on an emotional level, which may reflect previous defeat or results below the expected (Rohlfs et al., 2008), for example, or other demands outside the sporting context.

Insummary, theresults of thisstudyshowassociations between mood states and athletic performance. Particularly, fatigue and depression appear to decrease the chances of success, and the higher vigor levels appear to increase chances of success. Future research should look into other emotional factors that together with mood states, could contribute to finding answers about outstanding sporting performance, as well as to propose intervention techniques to achieve and also maintain those performance levels in the long term.

\section{REFERENCES}

Allen, J. B., \& De Jong, M. R. (2006). Sailing and sports medicine: A literature review. British Journal of Sports Medicine, 40(7), 587-593.

Beck, A. T., \& Clark, D. A. (1988). Anxiety and depression: An information processing perspective. Anxiety Research, 1(1), 23-36.

Beedie, C. J., Terry, P. C., \& Lane, A. M. (2000). The profile of mood states and athletic performance: Two meta-analyses. Journal of Applied Sport Psychology, 12(1), 49-68. doi:10.1080/10413200008404213

Bertollo, M., Saltarelli, B., \& Robazza, C. (2009). Mental preparation strategies of elite modern pentathletes. Psychology of Sport and Exercise, 10(2), 244-254.

Brandt, R., Viana, M. D. S., Segato, L., \& Andrade, A. (2010). Mood states sail athletes during the Pre-Panamerican. Motriz-Revista de Educacao Fisica, 16(4), 834-840.

Devonport, T. J., Lane, A. M., \& Hanin, Y. L. (2005). Emotional states of athletes prior to performance-induced injury. Journal of Sports Science and Medicine, 4(4), 382-394.

Dosil, J. (2004). Psicología de la actividad física y del deporte. Madrid: McGraw-Hill, Interamericana.

Galambos, S. A., Terry, P. C., Moyle, G. M., \& Locke, S. A. (2005) Psychological predictors of injury among elite athletes. British Journal of Sports Medicine, 39(6), 351-354. doi:10.1136/bjsm.2005.018440

Lane, A. M., \& Terry, P. C. (2000). The nature of mood: Development of a conceptual model with a focus on depression. Journal of Applied Sport Psychology, 12(1), 16-33. doi:10.1080/10413200008404211

Lane, A. M., Terry, P. C., Beedie, C. J., Curry, D. A., \& Clark, N. (2001). Mood and performance: Test of a conceptual model with a focus on depressed mood. Psychology of Sport and Exercise, 2(3), 157-172.
Lane, A. M., Whyte, G. P., Terry, P. C., \& Nevill, A. M. (2005). Mood self-set goals and examination performance: the moderating effect of depressed mood. Personality and Individual Differences, 39(1), 143153. doi:10.1016/j.paid.2004.12.015

LeUnes, A., \& Burger, J. (2000). Profile of mood states research in sport and exercise psychology: Past, present, and future. Journal of Applied Sport Psychology, 12(1), 5-15. doi:10.1080/10413200008404210

Manzanares, A., Menayo R., Segado, F., Salmerón, D., \& Cano J. A. (2015). A probabilistic model for analysing the effect of performance levels on visual behaviour patterns of young sailors in simulated navigation. European Journal of Sports Science, 15(3), 203-12.

Micklewright, D., Griffin, M., Gladwell, V., \& Beneke, R. (2005). Mood state response to massage and subsequent exercise performance. Sport Psychologist, 19(3), 234-250.

Morgan, W. P., Oconnor, P. J., Ellickson, K. A., \& Bradley, P. W. (1988). Personality structure, mood states, and performance in elite male distance runners. International Journal of Sport Psychology, 19(4), 247-263.

Olmedilla, A., Ortega, E., González, J., \& Serpa, S. (2015). Psychological training in sailing: Performance improvement for the Olympic classification phase. Universal Journal of Psychology, 3(4), 122-131. doi:10.13189/ujp.2015.030404

Pluims, J. P., Canãl-Bruland, R., Hoozemans, M. J., \& Savelsbergh, G. J. (2015). Visual search, movement behaviour and boat control during the windward mark roundin in sailing. European Journal of Sports Science, 33(4),398-410.

Rohlfs, I. C. P. D. M., de Carvalho, T., Rotta, T. M., \& Krebs, R. J. (2004). Aplicação de instrumentos de avaliação de estados de humor na 
detecção da síndrome do excesso de treinamento. Revista Brasileira de Medicina do Esporte, 10(2), 111-116.

Rohlfs, I. C. P. D. M., Rotta, T. M., Andrade, A., Terry, P. C., Krebs, R. J., \& de Carvalho, T. (2005). The Brunel of mood scale (BRUMS): instrument for detection of modified mood states in adolescents and adults athletes and non athletes. Fiep Bulletin, 75, 281-284.

Rohlfs, I. C. P. D. M., Rotta, T. M., Luft, C. D. B., Andrade, A., Krebs, R. J., \& de Carvalho, T. (2008). A Escala de Humor de Brunel (Brums): Instrumento para detecção precoce da síndrome do excesso de treinamento. Revista Brasileira de Medicina do Esporte, 14(3), 176-181.

Rotunno, R., Senarega, D., \& Reggiani, E. (2004). Psychological support in top level sailing. International Journal of Sport Psychology, 35(1), 13-22.

Schinka, J. A., Velicer, W. F., \& Weiner, I. B. (2003). Handbook of psychology: Research methods in psychology. New Jersey: Wiley.

Scott, J. P. R., McNaughton, L. R., \& Polman, R. C. J. (2006). Effects of sleep deprivation and exercise on cognitive, motor performance and mood. Physiology \& Behavior, 87(2), 396-408. doi:10.1016/j. physbeh.2005.11.009

Segato, L., Brandt, R., Liz, C., Vasconcellos, D., \& Andrade, A. (2010). Psychological stress in high level sailors during competition. Motricidade, 6(3), 53-62.

Shephard, R. J. (1997). Biology and medicine of sailing. An update. Sports Medicine, 23(6), 350-356.

Terry, P. C. (1995). The efficacy of mood state profiling with elite performers: A review and synthesis. Sport Psychologist, 9, 309-309.
Terry, P. C., \& Lane, A. M. (2000). Development of normative data for the profile of mood states for use with athletic samples. Journal Applied Sports Psychology, 12, 69-85.

Terry, P. C., Lane, A. M., \& Fogarty, G. J. (2003). Construct validity of the profile of mood states - adolescents for use with adults. Psychology of Sport and Exercise, 4(2), 125-139. doi:10.1016/s14690292(01)00035-8

Thelwell, R. C., Lane, A. M., \& Weston, N. J. V. (2007). Mood states, selfset goals, self-efficacy and performance in academic examinations. Personality and Individual Differences, 42(3), 573-583. doi:10.1016/j. paid.2006.07.024

Totterdell, P., \& Leach, D. (2001). Negative mood regulation expectancies and sports performance: An investigation involving professional cricketers. Psychology of Sport and Exercise, 2(4), 249-265.

Watson, D., Clark, L. A., \& Tellegen, A. (1988). Development and validation of brief measures of positive and negative affect - The PANAS Scales. Journal of Personality and Social Psychology, 54(6), 1063-1070. doi:10.1037/0022-3514.54.6.1063

Werneck, F. Z., Bara Filho, M. G., \& Ribeiro, L. C. S. (2006). Efeitos do exercício físico sobre os estados de humor: Uma revisão. Revista Brasileira de Psicologia do Esporte e Exercício, 0, 22-54.

Zandi, L., \& Rad, L. S. (2013). A comparison of the mood state profiles of winning and losing female athletes. European Journal of Experimental Biology, 3(1), 424-428. 